\title{
Identifying Service Quality Attributes and Measuring Customer Satisfaction of Dhaka-Pabna Route Public Bus Service
}

\author{
Md. Masud-Ul-Hasan", Md. Hasebur Rahman ${ }^{2}$, Masud Rana ${ }^{3}$ \\ ${ }^{1,3}$ Lecturer, Department of Business Administration, Pabna University of Science and Technology, BANGLADESH \\ ${ }^{2}$ Assistant Professor, Department of Business Administration, Pabna University of Science and Technology, BANGLADESH
}

\begin{abstract}
Dhaka is the capital city of Bangladesh. A notable number of people have to go to and return from Dhaka every day. Most of the people use bus service. The situation of Dhaka-Pabna route bus service is not exception of this. Gradually the number of customer as well as service provider is increasing in this route. As a result, the service providers are facing competition to attract and retain customer. Measuring customer satisfaction is very important in attracting and retaining customer. This study was intended to identify service quality attributes in the long route public bus transit service and measure the customer satisfaction by surveying a number of 250 respondents. Finding shows that, overall $13 \%$ customers are very satisfied, $48 \%$ customers are somewhat satisfied, $32 \%$ customers are somewhat dissatisfied and $7 \%$ customers are very dissatisfied. Some recommendations are also provided to attract and retain customer.
\end{abstract}

Keywords: Public bus transportation service, service quality attributes, customer satisfaction, service marketing

\section{INTRODUCTION}

Bangladesh is a country with huge population. Dhaka is the capital city of Bangladesh. The administration, business, education, health service and other service agency are very much centralized in Dhaka. That is the reason why a huge number of people live in Dhaka city. More than twelve million people live in Dhaka city. Day by day the number is increasing. At the same time a notable number of people enter and leave Dhaka daily from different district of Bangladesh. The per capita incomes of most of the people are low thus the standard of living is not high. Most of the people heavily rely on public transportation to go and return from Dhaka. Road, air, water and rail are the alternative public transit options for the people to and return from Dhaka. But due to various reasons most people use road transit that means public bus. Knowing this huge demand a notable number of branded and non-branded (local) bus companies are engaged in transportation business targeting the people who travels to and return from Dhaka. Dhaka-Pabna route is not exception to this. A number of 5 to 6 well known (branded) and some other non-branded bus companies are providing the transportation services in this route. The numbers of passenger as well as the number of buses are increasing in this route. With the establishment of a public university and a government medical college since 2008 the number of educated people from different districts has increased in Pabna. As a result the number of passenger and their expectation has increased. In this situation the some new bus companies have involved in this business and try to attract the customer. At the same time the existing bus companies are investing more to retain the existing customer and attracting new customer. This results a growing competition among bus companies. So every bus companies are trying to find out the way to attract and retain customer. Measuring customer satisfaction and taking action accordingly is an important way of attracting and retaining customer. To measure customer satisfaction it is important to identify the service quality attributes which affects customer satisfaction. This research study was an attempt to find out the service quality attributes which affects the customer satisfaction in long route bus transportation service and measure the level of customer satisfaction of Dhaka-Pabna bus route customer. Finally, some recommendations are also provided on the basis of research findings to improve the customer satisfaction.

\section{ObJectives OF the Study}

The study was accomplished to serve the following objectives:

- To identify the nature of the passenger and business of Dhaka-Pabna route bus service.

- To identify the service quality attributes which affect customer satisfaction for the customer in this route.

- To measure the satisfaction of customer in DhakaPabna route bus service.

- To provide some recommendation to improve the service quality and customer satisfaction in DhakaPabna route bus service. 


\section{LITERATURE REVIEW}

Kotler (1991) says now a days customer satisfaction are using as managerial tools of evaluating quality. Managers think a high customer satisfaction rating leads to a high profit in future. Satisfaction can be broadly defined as a post-purchase evaluation of product's perceived quality performance and theexpectation of the customer from those products.

Villanueva, Yoo, \& Hanssens (2008) show that acquisition of customer can be possible in two ways. By investing in marketing promotion companies can acquire customers but this way is costly. On the other hand a positive word-of-mouth communication can also attract customer in cheaper way. They also found that the acquisition rate is high in the earlier way than the later one. The authors shows that customer acquisition is more easy, sustainable and less costly when it is achieved through word-of-mouth communication.

Adelman \& Ahuvia (1995) found in his research that the role of social support in the form of word of mouth communication in a service business is very much important and its effect on clients' willingness to recommend the service is very strong.

Eboli \& Mazzulla (2007) proposed a tool for measuring customer satisfaction in public transport. Specifically, a structural equation model is formulated to explore the impact of the relationship between global customer satisfaction and service quality attributes. The public transport service analyzed is the bus service habitually used by University of Calabria students to reach the campus from the urban area of Cosenza (southern Italy). To calibrate the model, some data collected in a survey addressed to a sample of students were used.

Prioni \& Hensher (2000) develop a stated preference model of service quality choice that provides the set of indicators required to represent a user-based measure of service quality. The service quality index (SQI) provides an operationally appealing measure of service effectiveness to assist regulators in administering and monitoring a performance assessment management and operators in improving customer service.

Gilberta \& Wong (2003) conclude that understanding the relationship between airline service quality and profitability is important. However, it is perhaps more useful managerially to identify specific drivers of airline service quality that most relate to the passengers as appropriate intervention strategies can then be formulated. Based on the findings of the study it was found there are significant differences in service expectations among passengers of different ethnic groups/nationalities as well as passengers with different purposes of travel. However, there was no significant difference in service expectations between decisionmakers and non-decision-makers in choosing airlines.
Friman \& Fellesson (2009) analyze the relationship between the objective performance measures of public transport services and the satisfaction perceived by travelers. Several correlational analyses of their research show that the relationship between satisfaction and service performance in public transport is far from perfect. Anderson, Fornell, \& Mazvanchery (2004) connote that a growing body of empirical work supports the fundamental logic that customer satisfaction should positively influence customer retention. It is argued that by increasing retention, customer satisfaction secures future revenues and reduces the cost of future customer transactions, such as ones associated with communications, sales, and service. As a consequence, net cash flows should be higher. At the same time, greater customer retention indicates a more stable customer base that provides a relatively predictable source of future revenue as customers return to buy again, one that is less vulnerable to competition and environmental shocks.

Hanan \& Karp (1989) describe that Customer satisfaction can be experienced in a variety of situations and connected to both goods and services. It is a highly personal assessment that is greatly affected by customer expectations. Satisfaction also is based on the customer's experience of both contacts with the organization and personal outcomes.

Wallin Andreassen (1995) claimed that customer (dis)satisfaction in public transportation depends on three things: ticket price, price level and, finally, the layout of the platform or the station, especially for buses. Furthermore, he separates customers in two categories: one category are the ones who use public transportation very often and they are considered expertise users, to those who are not often users and they are not considered expertise. He found that (dis)satisfaction varies according to the above 3 factors (price, ticket price and layout) to 2 categories of customers. Expertise users consider those 3 factors very important in contrast to those who are not expertise in the use of public transportation.

\section{Methodology}

The research has been conducted based on both primary and secondary data. To identify the service quality attributes a pre questionnaire survey with fifty numbers of students of Pabna University and science and technology and twenty numbers of passengers at different bus counter of Dhaka-Pabna route were interviewed. Secondary data from related research and text book related to service marketing was also taken into consideration. Then after cross checking the primary data and secondary data researcher identified the service quality attributes for the long route bus transportation service. After identifying the service quality attributes a full length questionnaire survey was undertaken to 
measure the customer satisfaction of the long route bus transportation passenger Dhaka-Pabna route on the basis of previously identified service quality attributes. To measure customer satisfaction researcher firstly selects five bus companies serving in this route and then questioned fifty number of passenger for each service provider. Thus a total number of 250 respondents were selected from Pabna district that had an experience of travelling Dhaka-Pabna route bus transport service for at least one time. Convenient and random sampling method was used to collect data. The questionnaire was furnished by adopting various types of question both open ended question and close ended question. A five point Likert scale was used in this study. Researcher also used indepth interview to gain insight into long route bus service. A simple statistical method of mean and percentage was used to analyze data. Result was presented with table.

\section{FINDINGS}

\section{Demographic finding}

Among the total 250 number of respondents 210 were male and 40were female. Among the respondents 36\% normally loyal to Pabna Express, 24\% loyal to Sarker Travels, 18\% to ShaymolyParibahan and $12 \%$ to Raja-BadshaParibahan and $10 \%$ respondent normally loyal to others bus. From the total respondents $74 \%$ respondents reside in Pabna, $24 \%$ respondents reside in Dhaka and remaining $2 \%$ in others place. The age range of respondents consisted of $18 \%$ below 20 years of age, $46 \%$ is of $20-30$ years; $36 \%$ is $30-50$ years of age. $46 \%$ of the respondents were student; $24 \%$ of the respondents were service holder; $20 \%$ of the respondents were businessman; and $10 \%$ of the respondents were others. $42 \%$ of the respondents were married and $58 \%$ of the respondents were unmarried. The education level of the respondents is $4 \%$ below SSC and 10\% SSC and 30\% HSC and $36 \%$ bachelor and $20 \%$ were masters and above. Most of the respondents simultaneously use more than one operator. Of the total respondents $20 \%$ of the respondent's purpose of travel is business and $46 \%$ of the respondent's purpose of travel is education-shopping-medical treatment and $24 \%$ of the respondent's purpose of travel for going home and rest $10 \%$ of the respondent's purpose of travel was others. Most of the respondent's travel in this route in a month is more than one times and remaining is one or none. Most of the respondent's choice window and left side and remaining are choice right side and center. Normally the fare of service in this route is 300-340Tk for non-ac bus and 500-800Tk for ac bus.

\section{Service quality attributes}

A pre questionnaire survey results the following service quality attributes which has strong effect on customer satisfaction for the long route bus service. Those service quality attributes are then segmented into three heading, I.e. 8 attributes in the heading of before departure of the journey, 12 attribute in the bus and on the way heading and 4 attributes in after arrival of the destination heading.. Table 1 shows the detail about those service quality attributes.

Table 1: Service quality attributes of long route bus transportation service

\begin{tabular}{|l|}
\hline \multicolumn{1}{|c|}{ Before departure of the journey } \\
\hline - Ticket reservation over phone or mobile \\
- Reservation cancellation facilities \\
- Behavior of the counter staff \\
- Size and sitting arrangement of waiting room \\
- Wash room facilities in waiting room \\
- Availability of coaster service \\
- Luggage management service and efficiency by \\
counter staff \\
- Departure at right time \\
\hline - Seat arrangement \\
- Seat's comfortableness \\
- Ceiling's height \\
- Entertainment facilities \\
- Noise protection system \\
- Smoking zone \\
- Vomit management \\
- Internal security in the interval time \\
- Interruption free journey \\
- Interval management \\
- Security on the way during night journey \\
- Safe driving \\
\hline - After arrival of the destination \\
- - Luaster service facility \\
from the bus \\
counter \\
\hline
\end{tabular}

Before departure of the journey:

Table 2: Customer Satisfaction (Before departure of the journey)

\begin{tabular}{|c|l|c|c|c|c|}
\hline \multicolumn{2}{|c|}{$\begin{array}{c}\text { Service Quality Attributes } \\
\text { (Before departure of the journey) }\end{array}$} & $\begin{array}{c}\text { Very Satisfied } \\
\%\end{array}$ & $\begin{array}{c}\text { Somewhat Satisfied } \\
\%\end{array}$ & $\begin{array}{c}\text { Somewhat Dissatisfied } \\
\%\end{array}$ & $\begin{array}{c}\text { Very Dissatisfied } \\
\%\end{array}$ \\
\hline 1 & $\begin{array}{l}\text { Ticket reservation over phone or } \\
\text { mobile }\end{array}$ & 30 & 46 & 14 & 10 \\
\hline 2 & Reservation cancellation facilities & 14 & 42 & 38 & 6 \\
\hline 3 & Behavior of the counter staff & 16 & 48 & 28 & 8 \\
\hline
\end{tabular}


Asian Business Review, Volume 5, Number 2/2015 (Issue 11)

ISSN 2304-2613 (Print); ISSN 2305-8730 (Online)

\begin{tabular}{|c|l|c|c|c|c|}
\hline \hline 4 & $\begin{array}{l}\text { Size and sitting arrangement of } \\
\text { waiting room }\end{array}$ & 2 & 44 & 38 & 62 \\
\hline 5 & Wash room facilities in waiting room & 4 & 28 & 62 & 4 \\
\hline 6 & Availability of coaster service & 0 & 34 & 32 & 0 \\
\hline 7 & $\begin{array}{l}\text { Luggage management service and } \\
\text { efficiency by counter staff }\end{array}$ & 18 & 50 & 52 & 8 \\
\hline 8 & Departure at right time & 4 & 36 & $\mathbf{4 0}$ & $\mathbf{8}$ \\
\hline & Total Customer Satisfaction & 11 & $\mathbf{4 1}$ & & 6 \\
\hline
\end{tabular}

When asking to the respondents about Ticket reservation facilities 30\% respondents said they are very satisfied about this service quality attributes, $46 \%$ were somewhat satisfied, $14 \%$ were somewhat dissatisfied and $10 \%$ were very dissatisfied.

When asking to the respondents about Reservation cancellation facilities $14 \%$ respondents said they are very satisfied about this service quality attributes, $22 \%$ were somewhat satisfied, $38 \%$ were somewhat dissatisfied and $6 \%$ were very dissatisfied.

When asking to the respondents about Behavior of the counter staff $16 \%$ respondents said they are very satisfied about this service quality attributes, $48 \%$ were somewhat satisfied, $28 \%$ were somewhat dissatisfied and $8 \%$ were very dissatisfied.

When asking to the respondents about Size and sitting arrangement of waiting room $2 \%$ respondents said they are very satisfied about this service quality attributes, $44 \%$ were somewhat satisfied, $38 \%$ were somewhat dissatisfied and $16 \%$ were very dissatisfied.

When asking to the respondents about Wash room facilities in waiting room $4 \%$ respondents said they are very satisfied about this service quality attributes, $28 \%$ were somewhat satisfied, $62 \%$ were somewhat dissatisfied and $6 \%$ were very dissatisfied.

When asking to the respondents about Availability of coaster service $00 \%$ respondents said they are very satisfied about this service quality attributes, 34\% were somewhat satisfied, $62 \%$ were somewhat dissatisfied and $4 \%$ were very dissatisfied.

When asking to the respondents about Luggage management service and efficiency by counter staff $18 \%$ respondents said they are very satisfied about this service quality attributes, $50 \%$ were somewhat satisfied, $32 \%$ were somewhat dissatisfied and $00 \%$ were very dissatisfied.

When asking to the respondents about Departure at right time $4 \%$ respondents said they are very satisfied about this service quality attributes, 36\% were somewhat satisfied, $52 \%$ were somewhat dissatisfied and $8 \%$ were very dissatisfied.

Finally summing up the all eight service quality attributes $11 \%$ customer are very satisfied, $41 \%$ are somewhat satisfied, $40 \%$ somewhat dissatisfied and $8 \%$ are very dissatisfied in the segment of before departure of the journey.

In the bus and on the way

Table 3: Customer Satisfaction (In the bus and on the way)

\begin{tabular}{|l|l|c|c|c|c|}
\hline \multicolumn{2}{|c|}{$\begin{array}{c}\text { Service Quality Attributes } \\
\text { In the bus and on the way) }\end{array}$} & $\begin{array}{c}\text { Very } \\
\text { Satisfied \% }\end{array}$ & $\begin{array}{c}\text { Somewhat } \\
\text { Satisfied \% }\end{array}$ & $\begin{array}{c}\text { Somewhat } \\
\text { Dissatisfied \% }\end{array}$ & $\begin{array}{c}\text { Very } \\
\text { Dissatisfied \% }\end{array}$ \\
\hline 1 & Seat arrangement & 20 & 60 & 16 & 4 \\
\hline 2 & Seat's comfortableness & 26 & 52 & 22 & 0 \\
\hline 3 & Ceiling's height & 48 & 50 & 2 & 0 \\
\hline 4 & Entertainment facilities & 6 & 80 & 44 & 0 \\
\hline 5 & Noise protection system & 8 & 50 & 42 & 0 \\
\hline 6 & Smoking zone & 4 & 44 & 42 & 10 \\
\hline 7 & Vomit management & 12 & 36 & 24 & 28 \\
\hline 8 & Internal security in the interval time & 18 & 68 & 14 & 0 \\
\hline 9 & Interruption free journey & 0 & 58 & 28 & 14 \\
\hline 10 & Interval management & 12 & 60 & 24 & 4 \\
\hline 11 & Security on the way during night journey & 14 & 40 & 38 & 8 \\
\hline 12 & Safe driving & 10 & 76 & & $\mathbf{2}$ \\
\hline
\end{tabular}

When asking to the respondents about Seat arrangement, $20 \%$ respondents said they are very satisfied about this service quality attributes, $60 \%$ were somewhat satisfied, $16 \%$ were somewhat dissatisfied and $4 \%$ were very dissatisfied.
When asking to the respondents about Seat's comfortableness $26 \%$ respondents said they are very satisfied about this service quality attributes, 52\% were somewhat satisfied, $22 \%$ were somewhat dissatisfied and $0 \%$ were very dissatisfied. 
When asking to the respondents about Ceiling's height $48 \%$ respondents said they are very satisfied about this service quality attributes, 50\% were somewhat satisfied, $2 \%$ were somewhat dissatisfied and $0 \%$ were very dissatisfied.

When asking to the respondents about Entertainment facilities $6 \%$ respondents said they are very satisfied about this service quality attributes, $80 \%$ were somewhat satisfied, $14 \%$ were somewhat dissatisfied and $0 \%$ were very dissatisfied.

When asking to the respondents about Noise protection system $8 \%$ respondents said they are very satisfied about this service quality attributes, 50\% were somewhat satisfied, $42 \%$ were somewhat dissatisfied and $00 \%$ were very dissatisfied.

When asking to the respondents about Smoking zone facilities $4 \%$ respondents said they are very satisfied about this service quality attributes, $44 \%$ were somewhat satisfied, $42 \%$ were somewhat dissatisfied and $10 \%$ were very dissatisfied.

When asking to the respondents about Vomit management $12 \%$ respondents said they are very satisfied about this service quality attributes, 36\% were somewhat satisfied, $24 \%$ were somewhat dissatisfied and $28 \%$ were very dissatisfied.

When asking to the respondents about internal security in the interval time $18 \%$ respondents said they are very satisfied about this service quality attributes,
$68 \%$ were somewhat satisfied, $14 \%$ were somewhat dissatisfied and $0 \%$ were very dissatisfied.

When asking to the respondents about Interruption free journey $0 \%$ respondents said they are very satisfied about this service quality attributes, 58\% were somewhat satisfied, $28 \%$ were somewhat dissatisfied and $14 \%$ were very dissatisfied.

When asking to the respondents about Interval management $12 \%$ respondents said they are very satisfied about this service quality attributes, $60 \%$ were somewhat satisfied, $24 \%$ were somewhat dissatisfied and $4 \%$ were very dissatisfied.

When asking to the respondents about Security on the way during night journey $14 \%$ respondents said they are very satisfied about this service quality attributes, $40 \%$ were somewhat satisfied, 38\% were somewhat dissatisfied and $8 \%$ were very dissatisfied.

When asking to the respondents about Safe driving $10 \%$ respondents said they are very satisfied about this service quality attributes, $76 \%$ were somewhat satisfied, $10 \%$ were somewhat dissatisfied and $4 \%$ were very dissatisfied.

Finally summing up the all eight service quality attributes $15 \%$ customer are very satisfied, $56 \%$ are somewhat satisfied, $23 \%$ somewhat dissatisfied and $6 \%$ are very dissatisfied in the segment of in the bus and on the way.

\section{After arrival of the destination}

Table 4: Customer Satisfaction (After arrival of the destination)

\begin{tabular}{|c|c|c|c|c|c|}
\hline \multicolumn{2}{|r|}{$\begin{array}{l}\text { Service Quality Attributes } \\
\text { (After arrival of the destination) }\end{array}$} & $\begin{array}{c}\text { Very } \\
\text { Satisfied \% }\end{array}$ & $\begin{array}{l}\text { Somewhat } \\
\text { Satisfied \% }\end{array}$ & $\begin{array}{c}\text { Somewhat } \\
\text { Dissatisfied \% }\end{array}$ & $\begin{array}{c}\text { Very } \\
\text { Dissatisfied \% }\end{array}$ \\
\hline 1 & Right time arrival & 18 & 44 & 22 & 16 \\
\hline 2 & coaster service facility & 0 & 44 & 54 & 2 \\
\hline 3 & $\begin{array}{l}\text { Luggage management service after getting down from the } \\
\text { bus }\end{array}$ & 24 & 58 & 12 & 6 \\
\hline 4 & $\begin{array}{l}\text { In case of awkward time arrival, how do you satisfied } \\
\text { with the staying facility in the bus or in the counter }\end{array}$ & 16 & 38 & 42 & 4 \\
\hline \multicolumn{2}{|r|}{ Total Customer Satisfaction } & 15 & 46 & 32 & 7 \\
\hline
\end{tabular}

When asking to the respondents about Right time arrival $18 \%$ respondents said they are very satisfied about this service quality attributes, $44 \%$ were somewhat satisfied, 22\% were somewhat dissatisfied and 16\% were very dissatisfied.

When asking to the respondents about coaster service facility $0 \%$ respondents said they are very satisfied about this service quality attributes, $44 \%$ were somewhat satisfied, $54 \%$ were somewhat dissatisfied and $2 \%$ were very dissatisfied.

When asking to the respondents about Luggage management service after getting down from the bus $24 \%$ respondents said they are very satisfied about this service quality attributes, 58\% were somewhat satisfied, $12 \%$ were somewhat dissatisfied and $6 \%$ were very dissatisfied.
When asking to the respondents about In case of awkward time arrival, how do you satisfied with the staying facility in the bus or in the counter $16 \%$ respondents said they are very satisfied about this service quality attributes, 38\% were somewhat satisfied, $42 \%$ were somewhat dissatisfied and $4 \%$ were very dissatisfied.

Finally summing up the all eight service quality attributes $15 \%$ customer are very satisfied, $46 \%$ are somewhat satisfied, $32 \%$ somewhat dissatisfied and $7 \%$ are very dissatisfied in the segment of after arrival of the journey.

\section{Total customer satisfaction}

Combining the all three segments the overall customer satisfaction for the long route Dhaka-Pabna bus route indicates $13 \%$ customer are very satisfied, $48 \%$ are 
somewhat satisfied, 32\% somewhat dissatisfied and 7\% are very dissatisfied.

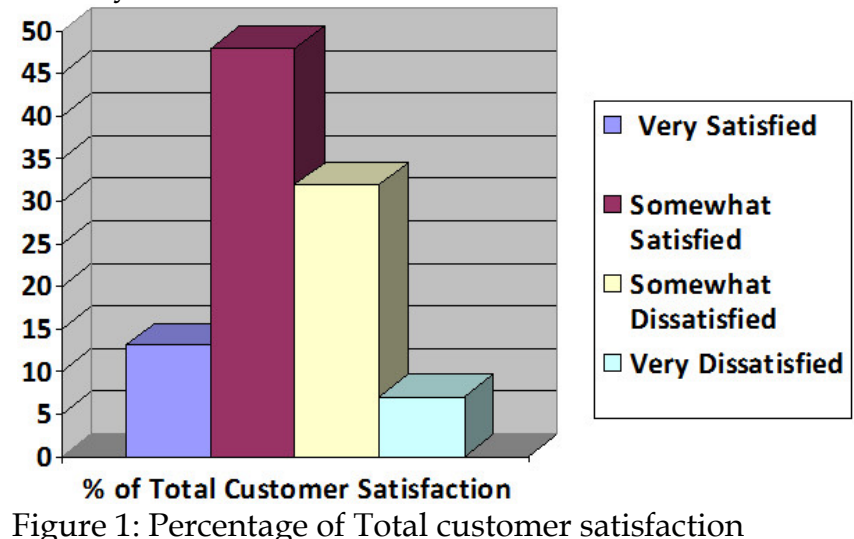

Figure 1: Percentage of Total customer satisfaction

\section{RECOMMENDATION}

As analysis shows the overall total customer satisfaction in the Dhaka-Pabna route bus service is $13 \%$ customers are very satisfied, $48 \%$ are somewhat satisfied, $32 \%$ of the customers are somewhat dissatisfied and rest 7\% customer are very satisfied, so the bus companies should maintain the service quality attributes to retain the existing satisfied customer to be satisfied and take some action to improve the performance of some quality attributes to improve the satisfaction level of the dissatisfied customer.

The bus service provider may conduct customer satisfaction survey which may give a positive signal to the customer that the service provider is aware about building and maintaining customer satisfaction. When the measuring customer satisfaction rating is favorable, then the firm may use the result in their advertising and spread the service and capture the market.

As finding shows that the majority numbers of customer are dissatisfied in the segment of before departure, so the service provider may consider to improve it. More specifically service provider may take action to improve the Size and sitting arrangement of waiting room and Wash room facilities in waiting room. Those two are suggested because only some one time fixed investment will require improving those two service attributes. As finding shows that most customers are dissatisfied about on time departure so the service provider should carefully handle this issue. Although finding shows that customer will be more satisfied if there is availability of coaster service but it is not suggested to add coaster service facility as it incur fixed investment as well as daily operating cost.

In the segment of in the bus and on the way, finding shows $(15+56)=71 \%$ customers are very satisfied and $(23+6)=29 \%$ customers are dissatisfied. Among dissatisfied customer most are unhappy about the Security on the way during night journey, Interruption free journey, Vomit management and Smoking zone. As in this segment there is a problem of boundary spanning personnel so the management of the service provider should strictly instruct and monitor the driver and supervisor to improve the
Security on the way during night journey, Interruption free journey, Vomit management.

In the segment of after arrival of the destination it is found $(13+48)=61 \%$ customers are satisfied where $39 \%$ customers are somewhat dissatisfied and very dissatisfied. The service provider may try to improve those attributes except coaster service facility as it incurs both fixed cost and variable cost. The service provider may classify their service category in two forms. One is no frill basic services for students and other low income customer. And another luxury business class for business man, executives and high income customer.

Most of all as finding shows that the fare of this route is Tk. 300-340 for non-ac bus and Tk. 500-800 for ac bus which is very competitive so the service provider should not add any extra cost unless it ensure logical revenue. Also it is found a growing number of customer of this route are students, teachers and service holder of Pabna university of science and technology so the service provider may be careful to attract those customer and also may establish a ticket counter in front of university campus.

\section{REFERENCES}

Abebe, E. (2014). The effect of service quality and core banking on customer satisfaction in commercial bank of Ethiopia. American Journal Of Trade And Policy, 1(2).

Adelman, M. B., \& Ahuvia, A. C. (1995). Social support in the service sector: the antecedents, processes, and outcomes of social support in an introductory service. Journal of Business Research, 32(3), 273-282.

Alam, N., \& Rubel, A. (2014). Impacts of Corporate Social Responsibility on Customer Satisfaction in Telecom Industry of Bangladesh. ABC Journal Of Advanced Research, 3(2), 26-37.

Anderson, E. W., Fornell, C., \& Mazvancheryl, S. K. (2004).Customer satisfaction and shareholder value.Journal of marketing, 68(4), 172-185.

Chowdhury, A., Chowdhury, M., \& Imran, M. (2015). Branding strategies for service firms- a study on the selected Internet Service Providers (ISPs) in Bangladesh. Asian Business Review, 2(1), 47-53.

Eboli, L., \& Mazzulla, G. (2007). Service quality attributes affecting customer satisfaction for bus transit. Journal of Public Transportation, 10 (3), 21-34

Friman, M., \& Fellesson, M. (2009). Service supply and customer satisfaction in public transportation: The quality paradox. Journal of Public Transportation, 12(4), 57-69.

Gebrehiwot, K. (2014). The impact of human capital development on economic growth in Ethiopia:Evidence from ARDL approach to cointegration. American Journal of Trade And Policy, 1(2).

Gilbert, D., \& Wong, R. K. (2003). Passenger expectations and airline services: a Hong Kong based study. Tourism Management, 24(5), 519-532.

Hanan, M., \& Karp, P. (1989).Customer Satisfaction: How to Maximize, Measure, and Market Your Company's" ultimate Product".American Management Association.

Islam, K., \& Salma, U. (2014). Customer Satisfaction of Internet Banking in Bangladesh: A Case Study on Citibank N.A. Asian Journal Of Applied Science And Engineering, 3(1), 53-64. 
Kotler, P. (1991). Marketing Management: Analysis, Planning, Implementation, and Control, 7th ed., NJ: .Englewood Cliffs Prentice Hall

Prioni, P., \& Hensher, D. A. (2000).Measuring service quality in scheduled bus services.Journal of Public Transportation, 3(2). 51-74

Roy, P. (2013). Wireless Internet Service and Customer Satisfaction: A Case Study on Young Generation in Bangladesh. Asian Journal of Applied Science And Engineering, 2(2), 96-102.

Sabur, M. (2015). Total Quality Management as a Tool for Decision Making. Asian Business Review, 3(4), 121-125.

Saha, A., Hasan, K., \& Uddin, M. (2015). A Conceptual Framework for Understanding Customer Satisfaction in Banking Sector: The Mediating Influence of Service Quality and Organisational Oath. American Journal Of Trade And Policy, 1(3), 39-48.

Shahabuddin, A. (2014). Eservice Quality for Customer Satisfaction Measurement: A Case Study on Islami Bank
Bangladesh Ltd. Global Disclosure Of Economics And Business, 3(1), 32-39.

Siddique, M., Akhter, M., \& Masum, A. (2015). Service Quality of Five Star Hotels in Bangladesh: An Empirical Assessment. Asian Business Review, 2(2), 67-72.

Uddin, S., Rahaman, M., \& Islam, M. (2015). Private Hospitals in Sylhet City, Bangladesh: An Issue of Service Marketing. Asian Business Review, 1(2), 103-105.

Villanueva, J., Yoo, S., \& Hanssens, D. M. (2008). The impact of marketing-induced versus word-of-mouth customer acquisition on customer equity growth.Journal of marketing Research, 45(1), 48-59.

Wallin Andreassen, T. (1995). (Dis) satisfaction with public services: the case of public transportation. Journal of Services Marketing, 9(5), 30-41.

Yunus, M., \& Rahman, M. (2014). Green Marketing for Creating Awareness for Green Consumerism. Global Disclosure Of Economics And Business, 3(1), 18-22.

$--0-$ 